Revista Electrónica Teoría de la Educación.

Educación y Cultura en la Sociedad de la Información.

http://www.usal.es/teoriaeducacion

Vol. 7. No2. Diciembre 2006

\title{
LAS EMOCIONES EN EL “TERRITORIO” ON-LINE
}

Se pone de relieve la importancia del sistema emocional para la realización de la experiencia social. Se analizan tres líneas de investigación acerca de la experiencia emocional en el contexto de las Tecnologías de la Información: las prácticas de la interacción mediadas por la tecnología, las relaciones computadora usuario y la tecnología informacional como instrumento para el reconocimiento y el análisis de la experiencia emocional.

Palabras clave: comunicación emocional en red, ordenadores emocionales, Affective Computing, reconocimiento computarizado de emociones.

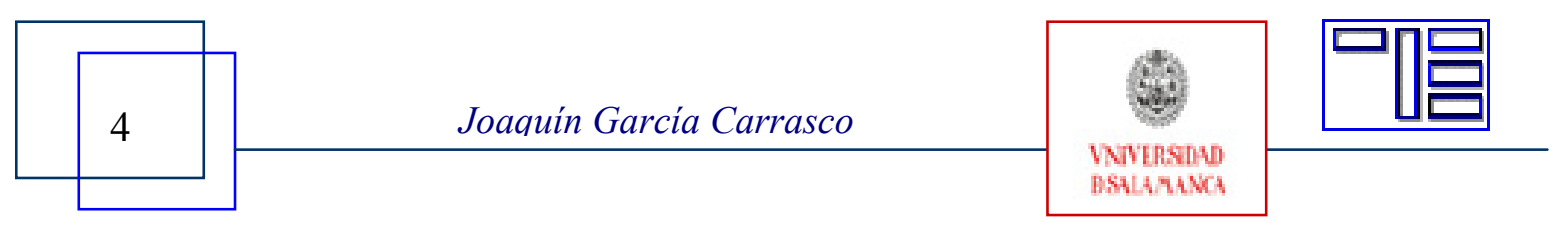




\section{THE EMOTIONS IN THE ON-LINE “COUNTRY”}

Importance of emotional system for the accomplishment of social experience is put of relief. Emotional experience in the context of Technologies of Information is analyzed from three lines of investigation: practices of human interaction through technology, relationships between user - computer and information technology as an instrument for recognition and analysis of emotional experience.

Keywords: emotional communication in social networks, emotional computers, Affective Computing, recognizing emotions through computers.

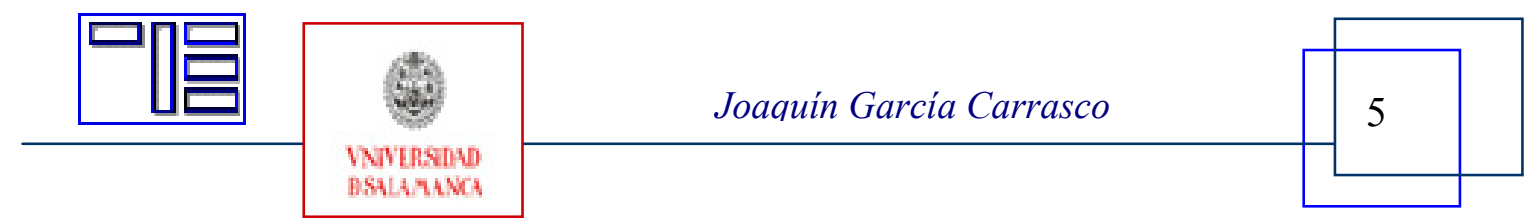


Revista Electrónica Teoría de la Educación.

Educación y Cultura en la Sociedad de la Información.

http://www.usal.es/teoriaeducacion

Vol. 7. No2. Diciembre 2006

\section{LES ÉMOTIONS DANS LE “TERRITOIRE" ON-LINE}

Cette étude met en relief l'importance du système émotionnel pour la réalisation de l'expérience sociale. On met l'accent sur l'analyse de trois lignes d'investigation au niveau de l'expérience émotionnelle dans le contexte des Technologies de L'information: les pratiques de l'interaction mises en œuvre par la technologie, les relations ordinateur/utilisateur et la technologie informationnelle en tant que instrument pour la reconnaissance et l'analyse de l'expérience émotionnelle.

Mots clés : Communication émotionnelle en réseau, ordinateurs émotionnels, Affective Computing, reconnaissance d'informatisation des émotions

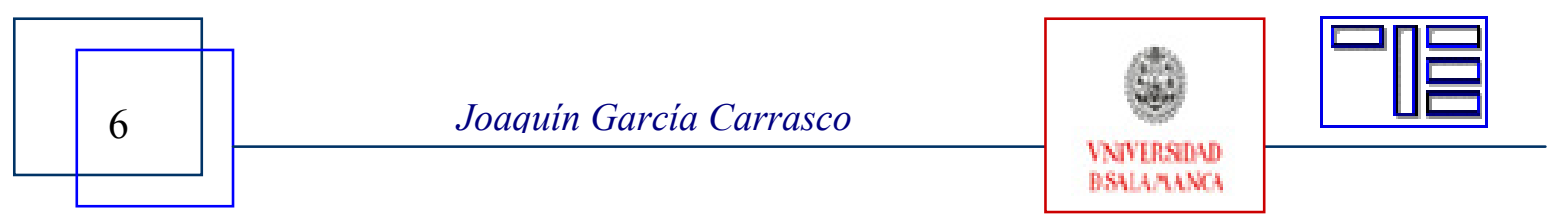




\section{LAS EMOCIONES EN EL “TERRITORIO” ON-LINE}

Prof. Dr. Joaquín García Carrasco.

carrasco@usal.es

Universidad de Salamanca.

\section{1.- LA DIALÉCTICA ENTRE EL VALOR DE LA RACIONALIDAD Y LA IM- PORTANCIA DEL OBJETIVO}

Tal vez no haya convicción más generalizada en la cultura occidental que la que identifica a la especie humana como animal racional. Las culturas y las épocas culturales se identifican, como afirmaba Ortega y Gasset, por la filiación a las creencias, por la configuración de lo que se suele denominar su sistema simbólico, resaltando el horizonte cognitivo con el que opera una comunidad cultural. Según esto, la cultura occidental ha estado afiliada a la convicción de que el estado de humanidad se sostiene en términos de racionalidad; por este motivo, resalta especialmente todo el sistema científico tecnológico y las funciones que $\mathrm{J}$. Bruner ${ }^{1}$ agrupa dentro de la que denomina mente paradigmáti$c a$. Ha sido y es evidente que hacia este objetivo canaliza hoy Occidente una corriente ingente de recursos, y hacia él convoca a las mentes más privilegiadas. Janez Potocnick, Comisario europeo de investigación lo ha declarado sin dejar dudas:

"Las infraestructuras de investigación son un elemento crítico de la construcción de la excelencia científica en Europa; no sólo pueden apoyar el trabajo de los científicos europeos, sino que las instalaciones de más alto nivel internacional ayudan a atraer a las mejores mentes científicas del mundo" (El País:20-10-2006, 33)

Con los andamios del Sistema Científico Tecnológico se edificaría la calidad de vida de la Humanidad, mejor decir el nivel de vida. Siendo esto cierto, tampoco hay evidencia más firme que la que da cuenta de que los seres humanos son unos sentimentales, independientemente de las épocas o de las culturas. Damos cuenta, también, de habilidades fantásticas en la expresión, comprensión y gestión de las intenciones y de las emociones, sentimientos, deseos y afectos; gestionamos con habilidad los conflictos sentimentales dialogando, dando muestras de lo que denomina J. Bruner, en el mismo texto, mente narrativa. También en el ámbito de la sentimentalidad se juegan los destinos de

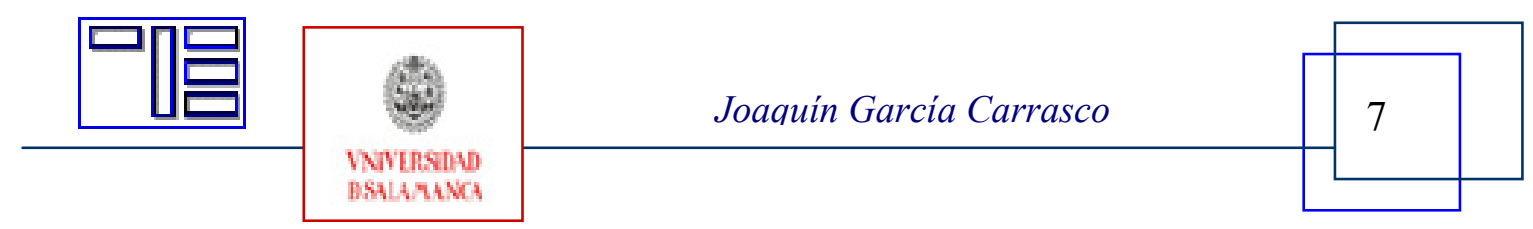


Revista Electrónica Teoría de la Educación.

Educación y Cultura en la Sociedad de la Información.

http://www.usal.es/teoriaeducacion

Vol. 7. No2. Diciembre 2006

la Humanidad, cuando lo que se busca es una "sociedad del conocimiento abierta, eficaz y democrática". El Parlamento Europeo recomendaba que el 7 Plan de Investigación en su capítulo 8, debiera garantizar el liderazgo europeo en la investigación en "ciencias socioeconómicas y humanidades" "2 todos los capítulos del 7 Plan se proyectaban en el horizonte de una búsqueda de desarrollo sostenible. Hoy, el concepto de sostenibilidad ya no hace referencia únicamente a la sostenibilidad de la biosfera, sino también a la insostenibilidad de una cultura que no tome en consideración la cohesión social, el entendimiento intercultural, la calidad de vida, la interdependencia mundial; estos son descriptores de una Sociedad sostenible, de una cultura sostenible, y metas para las funciones características de la mente narrativa. La promoción de estos objetivos constituye parte esencial de una "Sociedad moderna sostenible" y núcleo para la deliberación en el campo de las Humanidades.

Cada pulso de la vida y de las prácticas comunitarias, cada paso en la experiencia personal, va siendo elaborado como representación que se construye mediante patrones de significado y marcas valorativas; en estas marcas juegan un papel fundamental los que denomina A. Damasio "marcadores somáticos", son los que aportan el componente emotivo a las memorias experienciales y a los procesos relacionales con el mundo; porque toda experiencia es acontecimiento y proceso en una unidad psicosomática.

El 7 Programa Marco I+D de la U.E. propone un "Centro Común de Investigación", responde ese Centro a la convicción de que el futuro de Europa depende de la investigación, la producción y la gestión de la producción de energía y de los residuos que genera esta tecnología. La investigación común para la generación de una cultura sostenible, que genere la calidad de vida asociada a la cohesión social y al mutuo entendimiento, queda en el Documento como labor para el inmenso Colegio Invisible desde el que se promueve la salubridad del modo de vida. Pareciera que las políticas de la racionalidad únicamente se planifican para que existan infraestructuras que proporcionen la energía necesaria que necesita la casa donde los seres humanos actúan.

Al objetivo energético y de infraestructuras se convocan las mejores inteligencias, el resto -lo que corresponde a las metas finales de una Sociedad abierta, eficaz y democrática-, queda de la Responsabilidad de los sujetos empíricos (los particulares), los únicos a quienes parece atribuirse la condición de ser sujetos morales. Europa parece sólo sujeto de responsabilidad infraestructural, los europeos deben afrontar personalmente la responsabilidad moral dentro de las oportunidades que proporcionan las infraestructuras. La ciencia, no obstante aquel capítulo 8 sobre "ciencias socioeconómicas y humanidades", deja claro lo que contiene en su "noción", dejando los objetivos de las Humanidades en la zona a-política del texto, el que corresponde a la "declaración": la declaración de intenciones y la propuesta de metas finales. Todos los trabajadores en la educación quedan amparados y aludidos únicamente en la zona de la declaración previa y de los fines últimos. No obstante, todos estamos convencidos de que la educación de la mente narrativa, aquella en la que resolvemos nuestros conflictos relacionales en el mar de los sentimientos, juega un papel decisivo en el espacio para la sostenibilidad de la

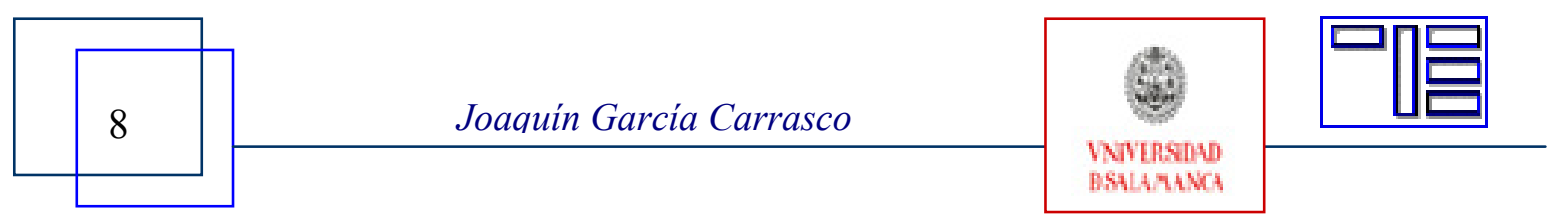


cultura, aunque pocos crean que ese objetivo tenga poder de convocatoria para las inteligencias más preclaras.

Dentro de las prácticas educativas de la humanidad también se plantean problemas capaces de satisfacer y de apabullar la más exigente de las curiosidades intelectuales. ¿Qué ocurre en la mente cuando cambia el contexto tecnológico en la Zona de Construcción de Actividad? ¿Cómo promover en la mente la consumación del entendimiento social? Para estas preguntas lo relevante no es el comportamiento de un átomo, sino que hay que atender el comportamiento de cada persona en lo cognitivo y en lo emocional. La transformación social, puesta la infraestructura, también depende del cambio acumulado y promovido por millones de personas.

"El cambio eficaz lo hacen quienes no esperan crear o transformar un sistema cerrado, sino que reconocen que el cambio efectivo tiene lugar en sistemas abiertos, donde la acumulación de acciones en común genera una armonía sorprendente"3

Un nuevo sistema abierto de interacción es lo que han creado las tecnologías informacionales cuyo producto más aparente es el que aludimos con el término Red, Internet; en ese sistema abierto juegan un papel de primera importancia las interacciones que alimentan la experiencia social y, dentro de ella, la componente emocional de la experiencia que alimenta la construcción histórica de la identidad personal. Este objetivo particular es el que justifica las páginas que siguen en este trabajo.

\section{2.- INTERNET COMO CAMPO DE DELIBERACIÓN SOBRE LOS PROCESOS DE FORMACIÓN}

La cultura, el proceso colectivo de incorporación cultural, la educación como tema de deliberación, puede cometer un error de bulto, disgregarse de ese "mundo tecnológico", por considerar que se trata del mundo de los tecnólogos, cuando los millones de usuarios demuestran que es uno de los "mundos" de una masa creciente de seres humanos, especialmente de adolescentes y jóvenes. ¿En qué mundo se delibera la educación, si no se delibera también en el mundo de la tecnología? Y, ¿de qué deliberación hablamos, si es deliberación desde el presentimiento acerca de la experiencia de otros? La deliberación sobre "los mundos de la cultura", sobre "los mundos de la educación", no puede dejar de ser deliberación para la gestión de la tecnología. Esto lo entendemos aquí en sentido fuerte: la teoría de la tecnología es un componente esencial de la teoría de la cultura y no una mera retórica moral sobre el empleo de la tecnología; lo cual afecta tanto al tecnólogo -porque toda tecnología conlleva para la humanidad la oportunidad y el riesgo-, como al filósofo moral, porque no hay modo de humanizar la humanidad sin la tecnología. En la emergencia conjunta de cultura y tecnología apareció el ser humano en la evolución: tanto en su condición de sujeto empírico de carne y hueso, como en su condición de sujeto moral. Llevar lo uno y lo otro de la mano constituyó, desde el principio, el problema pedagógico de la humanidad. Por eso, autores como Giddens ${ }^{4}$ o Gwinell ${ }^{5}$, advertían que la transformación profunda de los contextos de práctica mediados por las modernas tecnologías, llevaba consigo, modificaciones relevantes en los proce-

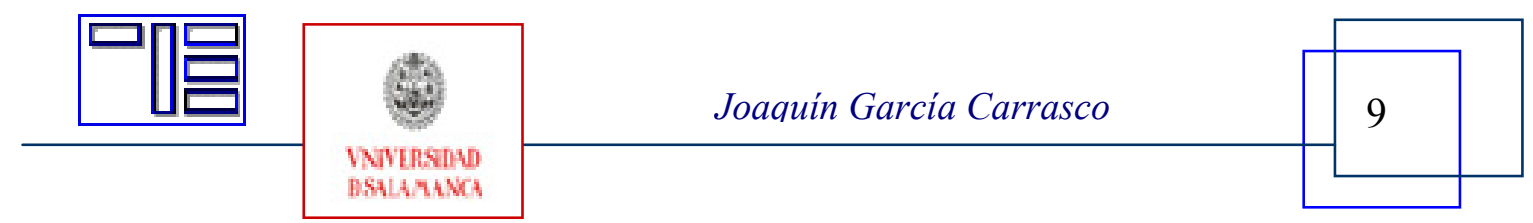


Revista Electrónica Teoría de la Educación.

Educación y Cultura en la Sociedad de la Información.

http://www.usal.es/teoriaeducacion

sos de elaboración, no sólo de la vida pública de los actores, en el espacio público, sino de la historia de las vivencias en la intimidad, en el espacio íntimo ${ }^{6}$, donde el sistema emocional juega su papel con indiscutible protagonismo.

Internet aparece en su uso más frecuente, para un número creciente de usuarios, como un entorno de comunicación y como un entorno de navegación, esto último en el sentido de vagabundeo informático y recorrido por contenedores de información, echando vistazos o buscando algo. Por este medio, el chateador y el cibernauta, expande el entorno relacional y el entorno de información en los que ejercita la praxis cultural; tanto la práctica de producir, intercambiar y controlar impresiones, mediante recursos diferentes a los que empleamos en la vida real (praxis comunicacional), como las prácticas de planificación, monitorización y gestión de los procesos productivos ( praxis en los sistemas técnicos). La Red podría describirse como un continente con zonas climáticas diferentes ( $W W W$, correo, foros, grupos de noticias, chats, $M U D$ ), nadie duda del impacto -mayor o menor, para bien o para mal-, sobre quienes entran en ella o se conectan a ella y participan de sus flujos. Si tomamos en cuenta su mediación técnica para las prácticas humanas, podríamos verla como instrumento psicológico, en términos de Kozulin ${ }^{7}$, dado su potencial para la elaboración de funciones mentales superiores; sirva de ejemplo la posibilidad de practicar la hiperlectura, el seguimiento no lineal o fractal de un tema, o practicar la elaboración de hipertextos multimedia, los cuales pueden ser consultados siguiendo itinerarios ramificados; también es un ejemplo la posibilidad de construir modelos dinámicos de sistemas complejos, permitiendo la función de deliberar (elaborar teoría) o aprender (comprender el funcionamiento) en entornos de simulación. Sin la red, hoy, no sería concebible el sistema científico tecnológico de la humanidad ni serían sostenibles los programas de investigación de mayor transcendencia. Si estimamos la reticularidad de las interacciones y sus constelaciones grupales, no obstante el carácter efímero y frágil de los grupos mediados por la computadora, Internet podría tomarse como un instrumento sociológico, un medio para la praxis de la socialización, en el que ni está ausente el sentimiento de grupo, ni se excluye la participación política o la cooperación humanitaria. Si peritamos la virtualidad de esta tecnología para la praxis de la incorporación cultural (educación), entonces podemos atribuir a la red la condición de instrumento pedagógico; instrumento pedagógico polivalente (navaja suiza) porque puede ser empleado para poner en pie auténticas instituciones culturales modulares, con módulos para la gestión del acceso, módulos tutoriales, módulos de creación de contenidos, módulos de evaluación de aprendizajes. Dado que contribuye, muchas veces de manera difusa y ambigua, para bien o para mal, a los "rituales de representación" 8 con los que vamos cincelando, sosteniendo o reparando la propia identidad, la red puede ser tomada como un dominio vital, tan heterogéneo, vulnerable y acechante como una selva tropical; para cada vez mayor número de personas se convierte en instrumento imprescindible de sus actividades ordinarias. Por todo ello, quien se ocupe en comprender el medio en el que los hombres definen su participación en la praxis cultural, no puede soslayar la consideración de tal mediación tecnológica de la acción en las comunidades contemporáneas. Hoy, todavía, respondiendo a los propósitos originales de la tecnología digital, ésta sigue haciendo hincapié especialmente en el almacenamiento, la búsqueda y

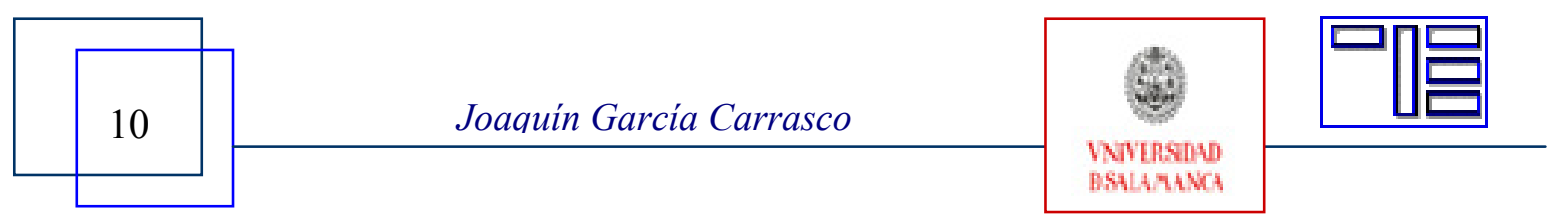


el acarreo de información. "Pero los programas y los servicios que necesitamos para poner la red al servicio de la interacción humana están mucho menos desarrollados [...] a medida que estos instrumentos informáticos de orientación social se vayan desarrollando y normalizando, iremos viendo cómo cambia la jerarquía social tradicional de Internet, en cuya cima se encuentran ahora las personas con más capacidad técnica"9. P. Wallace cree que estamos ante una tecnología social que otorga mucho poder al usuario, para bien o para mal.

De ahí la importancia de la creación de instituciones como el "Internet Interdisciplinary Institute (IN3)" de la UOC, o el "Observatorio de la Cibersociedad", en España. Constituyen nuevas maneras de tomar cuerpo institucional los proyectos colectivos de observar e investigar la cultura, son propuestas innovadoras para Institutos de Investigación en Ciencias de la Educación, nuevas responsabilidades para la Teoría y la Historia de la Educación, capítulos por escribir acerca de la Teoría y la Historia de las Instituciones Educativas Contemporáneas. Todo ello dentro de una perspectiva holárquica: vigencia, dentro de la vigencia, dentro de la vigencia; vigencia de la cultura informacional, dentro de la vigencia de la cultura lectoescritura, dentro de la vigencia de la cultura de oralidad. No ha cambiado el ser humano, le siguen doliendo las mismas cosas, han cambiado "mundos" en los que tiene que aprender a vivir y en los que tiene el deber de deliberar, tanto respecto a la cognición como respecto a la emoción; porque siempre acecha el riesgo de que todo quede en nada.

\section{3.- DOS CASOS EN EL ESPECTRO EMOCIONAL DE MILLONES DE BIO- GRAFÍAS}

En el primero me referiré únicamente al final de su historia ${ }^{10}$. Ella, con sesenta años, tiene una hija amorosa de treintaitantos años con Síndrome de Down profundo, cuya atención es una preocupación constante. Su segundo marido, antes habilísimo internauta, yace ahora derruido por un cáncer; un tumor cerebral desconecta la percepción de la realidad y la competencia lingüística; entiende lo que le comentan, pero es incapaz de encontrar las palabras adecuadas para la respuesta, convirtiendo su vida en un escenario habitualmente ininteligible para los demás, requiere de atención permanente, durante el día colaboran por turno tres personas; las noches, toledanas, sola con ellos dos, se transforman para mi amiga en un sobresalto constante. Con la ayuda de un sobrino, se entrenó en el manejo de Internet y encuentra, en el chateo con una sobrina casada en Perú, o con desconocidos de la red, asideros de distracciones y un charco emocional relajante y entretenido, que la alimenta y sostiene. "Sólo me relajo chateando", cuando todos en la casa duermen. Estos son los casos con los que defienden su perspectiva quienes trabajan en el ámbito de la cultura "tecnointegrados", por concentrar la deliberación en las virtualidades de la tecnología, en las prácticas realizativas que ofrece la tecnología, rompiendo las barreras de un "espacio relacional" agobiante. Sin esa tecnología el espacio real, según manifiesta ella, mantiene un agobio sin salida; con la tecnología, su espacio vital se expande y el imaginario aporta momentos de experiencia respirable y recuperadora. Justificaremos en el trabajo esta alusión al imaginario.

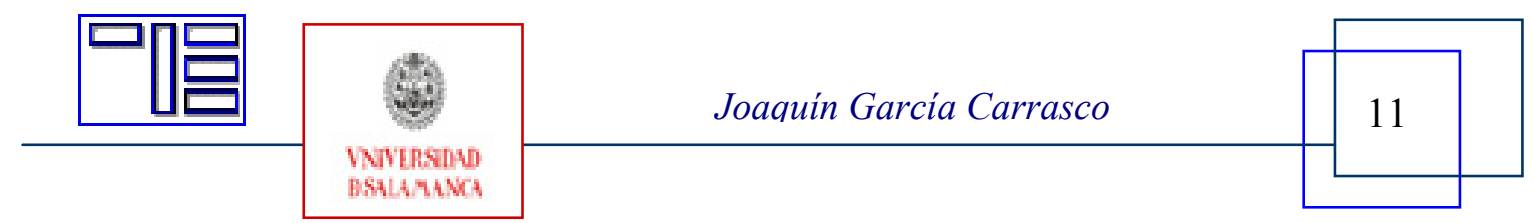


Revista Electrónica Teoría de la Educación.

Educación y Cultura en la Sociedad de la Información.

http://www.usal.es/teoriaeducacion

Vol. 7. No2. Diciembre 2006

El otro caso lo cuenta en uno de sus libros Diego Levis. Una pareja en la que ella gusta de chatear por canales de amor y amistad y él le escribe los textos. La historia la concibe ella, literariamente la elabora él. Cuando la boda se aproxima abandonan la afición; ella en secreto la retoma, profundizando en sus fantasías e insatisfacciones, termina citándose, viviendo tórridas noches de amor en las que únicamente se valora el clímax de cada encuentro. El novio la descubre y la despide, porque no quiere casarse con "la puta de Internet" $"$. A esta categoría de casos podrían recurrir quienes deliberan sobre la tecnología desde el presentimiento de una "tecnoapocalipsis", quienes con argumentos y evidencias de destrucción y desastres señalan con el dedo el no menos inmenso bajo fondo de Internet, el lumpen del ciberespacio, la profunda contaminación antropológica procedente de la red.

La coincidencia entre estos extremos del espectro a que hacen referencia ambas biografías deja patente lo que ya Freud en 1920 calificaba de "malestar de la cultura": todas las culturas son ambiguas, contienen en su estructura situaciones y condiciones para bien y para mal. De ahí la necesidad de deliberación constante, de pensamiento crítico y de voluntad profesional para que el proceso de incorporación cultural edifique la Zona de Construcción del Sujeto, minimizando las condiciones que pueden llevar a su destrucción o a que sus vidas queden en nada, en una humanidad superflua.

Desde el 6-8-1991 en que Berners-Lee publicó el código del World Wide Web (www), guiado por la sencilla idea de que el usuario no tuviera que preocuparse por la tecnología que ocultaba el proceso, nacieron las direcciones http://, que utilizan (según datos V2006) 694 millones de personas de más de 15 años, especialmente jóvenes, porque para ellos es una tecnología transparente. En el 2006, Internet supera a la prensa, por primera vez, como fuente de información ${ }^{12}$ y el $90 \%$ del tráfico de Telefónica en España usa el protocolo de Internet. El 20\% de los usuarios -los que utilizan la banda ancha a través del sistema ADSL- ocupan el 80 del tráfico; las "llamadas" de voz suponen el 20\% y el acceso a redes $\mathrm{P} 2 \mathrm{P}$ el $71 \%$ del consumo de banda ancha ${ }^{13}$. En otros términos, la música y el juego ocupan la mayor parte del espacio de banda disponible; si a ello se añade la comunicación en grupos de discusión, mensajería y "chateos", Internet es un inmenso charco para que ingentes masas de individuos chapoteen en las emociones.

\begin{tabular}{|c|c|c|c|c|c|c|}
\hline \multicolumn{7}{|c|}{ ESTADISTICAS MUNDIALES DE INTERNET Y DE POBLACIÓN } \\
\hline Regiones & $\begin{array}{l}\text { Población } \\
\text { ( } 2006 \text { Est.) }\end{array}$ & $\begin{array}{l}\text { \% Pobla- } \\
\text { ción } \\
\text { Mundial }\end{array}$ & $\begin{array}{l}\text { Usuarios, } \\
\text { dato } \\
\text { más reciente }\end{array}$ & $\begin{array}{l}\text { \% Población } \\
\text { (Penetración) }\end{array}$ & $\begin{array}{lr}\% & \text { Uso } \\
\text { Mundial }\end{array}$ & $\begin{array}{l}\text { Crecimiento } \\
\text { ( 2000-2005 } \\
\text { ) }\end{array}$ \\
\hline África & $915,210,928$ & $14.1 \%$ & $22,737,500$ & $2.5 \%$ & $2.2 \%$ & $403.7 \%$ \\
\hline Asia & $3,667,774,066$ & $56.4 \%$ & $364,270,713$ & $9.9 \%$ & $35.7 \%$ & $218.7 \%$ \\
\hline Europa & $807,289,020$ & $12.4 \%$ & $290,121,957$ & $35.9 \%$ & $28.5 \%$ & $176.1 \%$ \\
\hline Oriente Medio & $190,084,161$ & $2.9 \%$ & $18,203,500$ & $9.6 \%$ & $1.8 \%$ & $454.2 \%$ \\
\hline Norte América & $331,473,276$ & $5.1 \%$ & $225,801,428$ & $68.1 \%$ & $22.2 \%$ & $108.9 \%$ \\
\hline
\end{tabular}

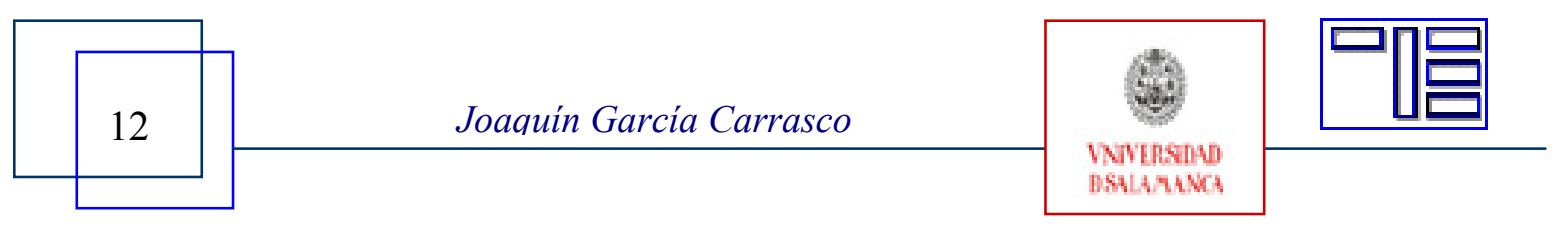


Revista Electrónica Teoría de la Educación.

Educación y Cultura en la Sociedad de la Información.

\begin{tabular}{|l|c|c|c|c|c|c|}
\hline $\begin{array}{l}\text { Latinoamérica } \\
\text { Caribe }\end{array}$ & $553,908,632$ & $8.5 \%$ & $\mathbf{7 9 , 0 3 3 , 5 9 7}$ & $14.3 \%$ & $7.8 \%$ & $337.4 \%$ \\
\hline $\begin{array}{l}\text { Oceanía / Austra- } \\
\text { lia }\end{array}$ & $33,956,977$ & $0.5 \%$ & $\mathbf{1 7 , 6 9 0 , 7 6 2}$ & $52.9 \%$ & $1.8 \%$ & $132.2 \%$ \\
\hline $\begin{array}{l}\text { TOTAL MUN- } \\
\text { DIAL }\end{array}$ & $6,499,697,060$ & $100.0 \%$ & $\mathbf{1 , 0 1 8 , 0 5 7 , 3 8 9}$ & $15.7 \%$ & $100.0 \%$ & $182.0 \%$ \\
\hline
\end{tabular}

NOTA: (1) Las Estadísticas de Usuarios Mundiales del Internet fueron actualizadas en Enero 31, 2006. (2) Para información detallada del país o región, de un clic sobre la región o país correspondiente. (3) Los datos de población se basan en las cifras actuales de world gazetteer. (4) Los datos de usuarios provienen de información publicada por Nielsen//NetRatings, ITU, NICs, ISPs y otras fuentes confiables. (6) Pueden consultarse en www.exitoexportador.com. (17-8-2006)

\section{USUARIOS DE INTERNET EN LA UNION EUROPEA}

\begin{tabular}{|c|c|c|c|c|c|c|}
\hline $\begin{array}{l}\text { UNION } \\
\text { EUROPEA }\end{array}$ & $\begin{array}{l}\text { Población } \\
\text { (Est. 2004) }\end{array}$ & $\begin{array}{l}\text { Usuarios, } \\
\text { en } 2000\end{array}$ & $\begin{array}{l}\text { Usuarios, } \\
\text { dato } \\
\text { mas reciente }\end{array}$ & $\begin{array}{l}\text { Crecimiento } \\
(2000-2004)\end{array}$ & $\begin{array}{l}\text { Penetración } \\
(\% \quad \text { Pobla- } \\
\text { ción })\end{array}$ & $\begin{array}{l}\% \\
\text { Tabla }\end{array}$ \\
\hline Alemania & $82,633,200$ & $24,000,000$ & $45,357,649$ & $89.0 \%$ & $54.9 \%$ & $23.0 \%$ \\
\hline Austria & $8,022,300$ & $2,100,000$ & $3,730,000$ & $77.6 \%$ & $46.5 \%$ & $1.9 \%$ \\
\hline Bélgica & $10,367,900$ & $2,000,000$ & $3,769,123$ & $88.5 \%$ & $36.4 \%$ & $1.9 \%$ \\
\hline Chipre & 950,400 & 120,000 & 210,000 & $75.0 \%$ & $22.1 \%$ & $1.3 \%$ \\
\hline Dinamarca & $5,405,600$ & $1,950,000$ & $3,375,850$ & $73.1 \%$ & $62.5 \%$ & $1.7 \%$ \\
\hline Eslovaquia & $5,381,200$ & 650,000 & $1,375,800$ & $111,7 \%$ & $25.6 \%$ & $0.7 \%$ \\
\hline Eslovenia & $1,954,500$ & 300,000 & 750,000 & $150.0 \%$ & $38.4 \%$ & $0.4 \%$ \\
\hline España & $41,895,600$ & $5,387,800$ & $14,445,289$ & $168.1 \%$ & $34.5 \%$ & $7.3 \%$ \\
\hline Estonia & $1,238,300$ & 366,600 & 444,000 & $21.1 \%$ & $35.9 \%$ & $0.2 \%$ \\
\hline Finlandia & $5,224,800$ & $1,927,000$ & $2,650,000$ & $37.5 \%$ & $50.7 \%$ & $1.3 \%$ \\
\hline Francia & $59,494,800$ & $8,500,000$ & $22,593,841$ & $165.8 \%$ & $38.0 \%$ & $11.4 \%$ \\
\hline Grecia & $11,208,400$ & $1,000,000$ & $1,718,400$ & $71.8 \%$ & $15.3 \%$ & $0.9 \%$ \\
\hline Holanda & $16,364,500$ & $3,900,000$ & $10,806,328$ & $177.1 \%$ & $66.0 \%$ & $5.5 \%$ \\
\hline Hungría & $10,117,900$ & 715,000 & $1,600,000$ & $123.8 \%$ & $15.8 \%$ & $0.8 \%$ \\
\hline Irlanda & $4,019,100$ & 784,000 & $1,319,608$ & $68.3 \%$ & $32.8 \%$ & $0.7 \%$ \\
\hline Italia & $56,153,700$ & $13,200,000$ & $28,610,000$ & $116.7 \%$ & $50.9 \%$ & $14.5 \%$ \\
\hline Latvia (Letonia) & $2,262,000$ & 150,000 & 936,000 & $524.0 \%$ & $41.4 \%$ & $0.5 \%$ \\
\hline Lituania & $3,494,700$ & 225,000 & 695,000 & $208.9 \%$ & $19.9 \%$ & $0.4 \%$ \\
\hline Luxemburgo & 457,700 & 100,000 & 165,000 & $65.0 \%$ & $36.0 \%$ & $0.1 \%$ \\
\hline Malta & 383,600 & 40,000 & 120,000 & $200.0 \%$ & $31.3 \%$ & $0.1 \%$ \\
\hline Polonia & $38,158,100$ & $2,800,000$ & $8,970,000$ & $220.4 \%$ & $23.5 \%$ & $4.5 \%$ \\
\hline
\end{tabular}

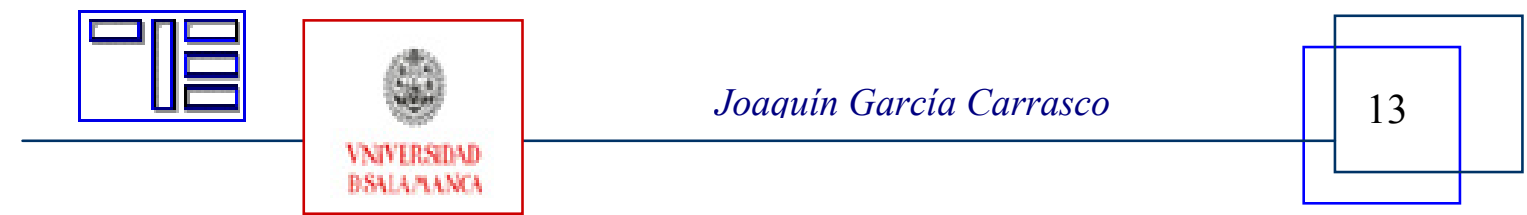


Revista Electrónica Teoría de la Educación.

Educación y Cultura en la Sociedad de la Información.

http://www.usal.es/teoriaeducacion

Vol. 7. No2. Diciembre 2006

\begin{tabular}{|l|l|l|l|l|l|l|}
\hline Portugal & $10,389,800$ & $2,500,000$ & $2,000,000$ & $-20.0 \%$ & $19.2 \%$ & $1.0 \%$ \\
\hline Reino Unido & $59,157,400$ & $15,400,000$ & $35,831,432$ & $132.7 \%$ & $60.6 \%$ & $18.2 \%$ \\
\hline Republica Checa & $10,287,100$ & $1,000,000$ & $2,700,000$ & $170.0 \%$ & $26.2 \%$ & $1.4 \%$ \\
\hline Suecia & $8,995,900$ & $4,048,000$ & $6,906,110$ & $70.6 \%$ & $76.8 \%$ & $3.5 \%$ \\
\hline Unión Europea & $454,018,500$ & $91,063,400$ & $197,349,430$ & $116.7 \%$ & $43.5 \%$ & $100.0 \%$ \\
\hline
\end{tabular}

NOTA: (1) Las estadísticas de la Unión Europea fueron actualizados a Junio 30 del 2.004. (2) Las cifras en detalle están contenidas en las páginas correspondientes a cada región y país. (3) Las cifras de población se basan en los datos actuales de gazetteer.de. (4) Los datos mas recientes de usuarios corresponden a datos de Nielsen-NetRatings, ITU, NICs, ISPs y otras fuentes locales. (5) Las cifras de crecimiento se determinaron comparando el dato actual de usuarios con el dato del año 2.000, tomado de las estadísticas del ITU. (6) Los datos proceden de " ExitoExportador.com ". (17-8-06)

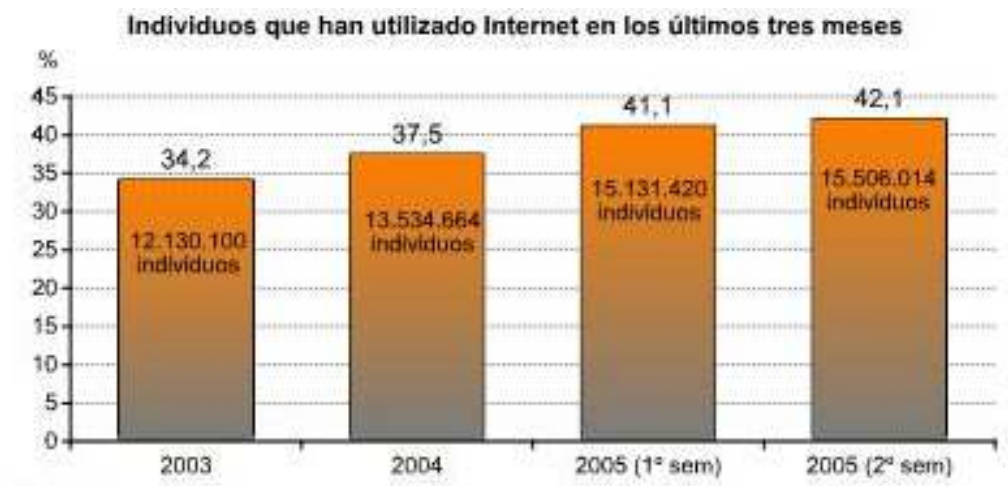

Fuente: INE

Fte: http://observatorio.red.es/indicadores/areas/ciudadanos/internet/individuos_internet.html (17-8-06)

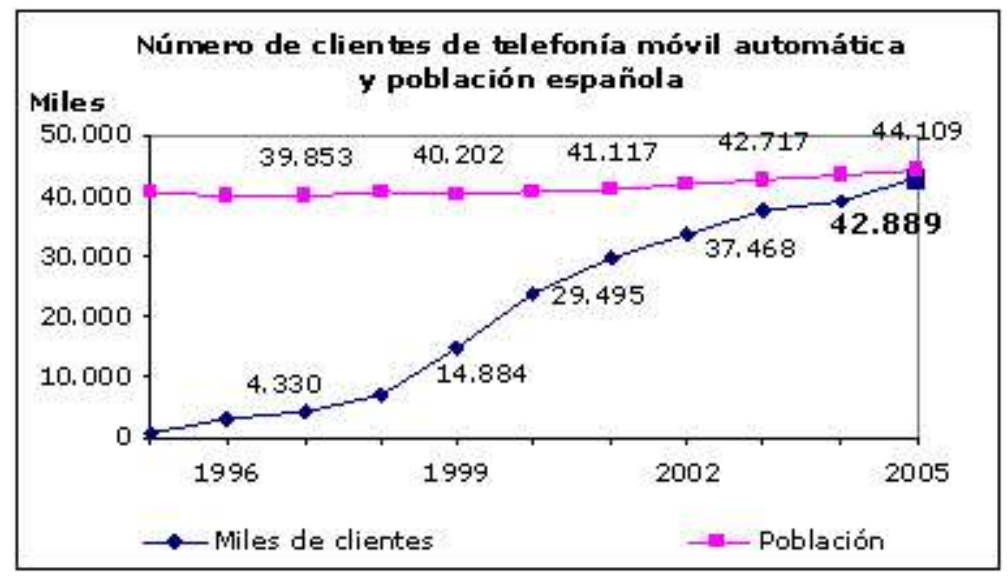

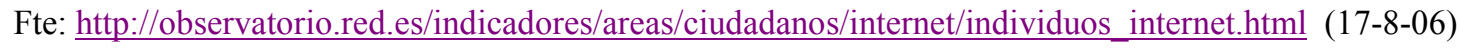

La estadística española (5-2006) para una población de más de 14 años (37.439 miles) es de 13.935 miles de usuarios de Internet (37,2\%); el 57,5\% se conectó “ayer"; $57,4 \%$

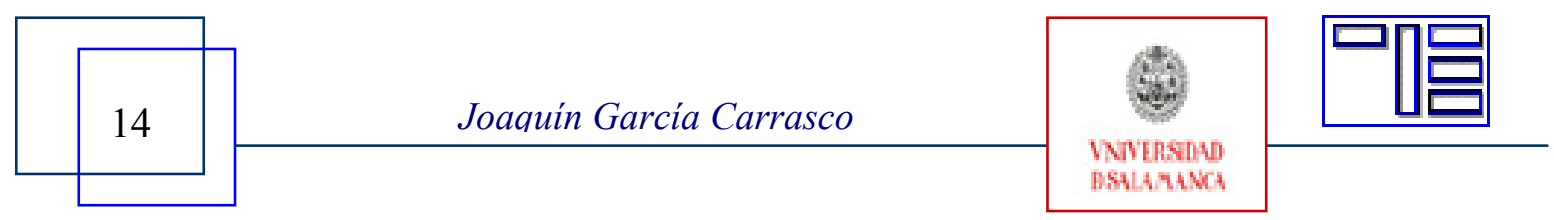


eran varones y el 42,6\% mujeres; el grupo de edad más conectado es el de 25-34 años (29,9 \%) y el menos conectado es el de 55-64 años (5,2 \%), el de 14-19 años (15,3\%); los usuarios pertenecientes a la clase media representan el 47,7\%; el 68,8\% se conecta desde casa y el 9,1\% desde la Universidad o desde su centro de estudios; este dato proporciona indicio de que el uso de la tecnología se extiende como una mancha de aceite por los escenarios de la vida diaria y está retenida su entrada, como práctica habitual, aunque exista infraestructura, como mediación sistemática en las prácticas de formación. Entre los objetivos de la conexión estuvieron: para un 95,1\%, el rastreo en www; para un 85,3\%, el correo electrónico, el 41,7 realizó mensajería instantánea, el 24,9\% transferencia de ficheros, el 25,4\% transferencia de ficheros P2P, el 17,2 \% chats; únicamente el $6,3 \%$ participó en grupos de discusión ${ }^{14}$.

De estas estadísticas puede concluirse que estamos ante una tecnología de uso masivo, ante un medio de comunicación en expansión exponencial y ante un mundo de prácticas compartidas en el que, en medida creciente, transcurre una parte de la vida social de las personas. De manera especial, en ese mundo, toma forma y se alimenta la experiencia emocional de una masa de población creciente, con tiempos de dedicación cada vez más altos.

Desde el punto de vista en el que me sitúo en este trabajo, el comportamiento emocional y el contexto de prácticas on-line, detecto al menos tres grandes líneas de investigación.

\section{I-La emoción en el "mundo" de las prácticas mediadas por la tecnología informática}

Sherry Turkle (1948-), que desde 1976 trabaja en el MIT, como investigadora de sociología de la ciencia, se dedicó especialmente a la relación entre los seres humanos y las computadoras. Considera el instrumento desde la perspectiva de la subjetividad en la máquina ("máquina subjetiva"), en el sentido de la medida en la que la máquina es incorporada a la subjetividad, como instrumento psicológico que diría Kozulin (1994) ${ }^{15}$, modificando la ecología del espíritu ${ }^{16}$, transformando los hábitos sociales, influyendo en la identidad y en los procesos de incorporación cultural. Resultaron innovadoras y estimuladoras de investigaciones, conocidas obras de S. Turkle "La vida en la pantalla"17, o "El segundo yo"18. Considera la autora, p.e. los MUD, los lugares multiusuario, en cualquiera de sus formatos, como una "nueva forma de literatura de creación colectiva", con homología respecto al teatro de la calle o la dramatización libre; al practicar en los MUD, no sólo se transforman en autores de su texto, sino que, con ello, continúan la autoría de su identidad, mediante nuevas formas de participación social; sobre todo, si se tiene en cuenta que su implicación en el escenario es tanto cognitiva como emocional.

Tal vez los MUD, "mazmorras multiusuario"19, esta quinta dimensión lúdica ${ }^{20}$ constituye un ejemplo paradigmático de comunidades sociales emergentes con participación emocional. En muchos casos, los usuarios tienen oportunidad de modificar y mejorar los diseños de juego originales ("MOD”); el movimiento juvenil de 1958, entonces

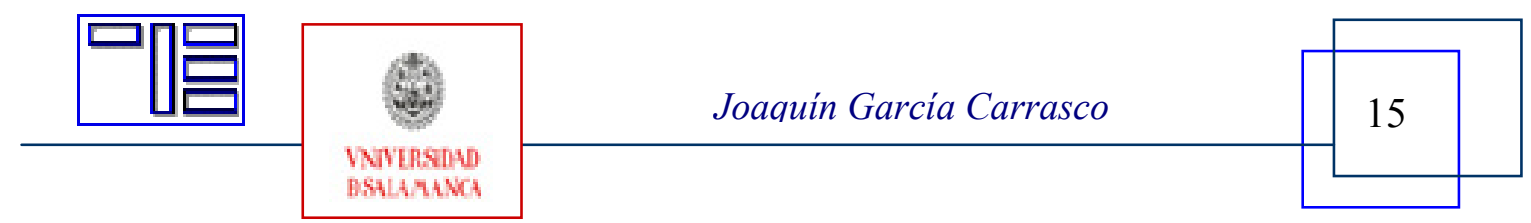


Revista Electrónica Teoría de la Educación.

Educación y Cultura en la Sociedad de la Información.

http://www.usal.es/teoriaeducacion

Vol. 7. No2. Diciembre 2006

aglutinado en torno a gustos musicales ${ }^{21}$, hoy se expande creando comunidades lúdicas de gustos tecnológicos ${ }^{22}$. Los más hábiles pueden incluso modificar la apariencia de los personajes, su "presentación pública", haciendo coherente lo que el personaje hace y lo que de él emana, aumentando el potencial expresivo emocional del escenario ${ }^{23}$.

\section{- El anonimato y la significación social de una comunidad on-line}

Una de las reservas más importantes que los críticos presentan respecto de estas comunidades y respecto de otras formas de interacción en la red es la impersonalidad. Sin embargo, el anonimato, para muchos un factor limitante de la plenitud de relación, contribuye a la explicitación de aspectos menos explorados de sí mismo, dentro de los escenarios públicos habituales. La expresión del yo en cuanto tal constituye un instrumento básico de la construcción de la identidad, aunque no exista propiamente un público que la identifique, se beneficie de ella o la valore. En el anonimato se fundamentaba la liberación transgresora de las medievales "fiestas de locos", la de los carnavales, la libertad de mirada que favorecen las gafas de sol, el ocultamiento identitario que produce la salida a lugares extraños para quedar exonerados de las restricciones de los espacios públicos de referencia personal ${ }^{24}$.

Al analizar la comunicación en Internet, se resalta, sobre todo, el anonimato del actor, una relación en la que la declaración de identidad puede ser falsa, en cualquier caso no comprobable. Pero, especialmente en el caso de los sentimientos morales, lo que derruye las restricciones en la conducta moral, es propiamente el anonimato de los observadores. La identificación del observador funciona como un atractor de sentimientos morales tan importantes como la vergüenza o la compasión ${ }^{25}$. M. Nussbaum dedica un amplio estudio a la importancia social de los sentimientos de "repugnancia", "vergüenza", "indignación". Esta falta de deliberación sobre la identidad de una víctima justifica para H. Arendt lo que denomina la "banalidad del mal", puede perder todo su relieve moral la conducta inmoral por la cosificación de la identidad del observador, se debilita el poder generador de sentimientos morales del público. Evidentemente, no se trata de una identificación meramente empírica, sino de la identificación del observador como referente moral, la carga semántica que lleva la condición de ser humano. Los sentimientos morales son alimentados por "rostros", por identidades reconocidas y valoradas. Una parte decisiva de la deliberación moral la compone ese pensar en el otro que lleva a su reconocimiento como semejante, como modelo de la propia identidad.

Los imaginados lugares del ciberespacio ofrecen mundos paralelos de sí mismo, territorios fantásticos o en la fantasía, cuya frecuencia de habitación termina por formar parte de la vida real de los actores. No se trata solamente de una ingerencia lúdica del imaginario en la vida real, ni una mera huida de la vida real para ensimismarse en el imaginario, sino que se trata propiamente de una interferencia en el significado habitual de lo que entendíamos por dominios de la identidad y de la autenticidad ${ }^{26}$, interferencia que puede terminar modificando, tanto la identidad como la autenticidad. En todo caso, estamos ante nuevos dominios de prácticas culturales. El denominado proceso de globali-

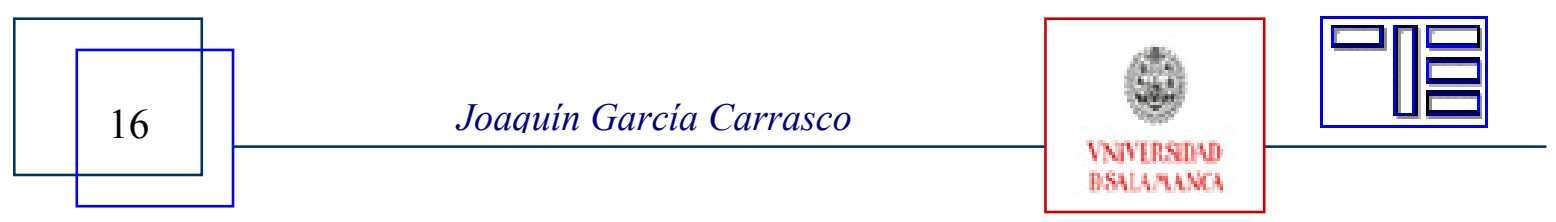


zación camina en la misma ola que el proceso de la intimidad. La globalización nos confronta con nuevas formas de actividad y nuevas relaciones con la intimidad ${ }^{27}$. Constituye una evidencia del hecho el creciente empleo de Internet como entorno en el que buscar e instituir "ciberparejas" 28 . Al mismo tiempo plantea la necesidad de investigar el nuevo contexto de prácticas sociales donde la socialidad se practica dentro de rituales de simulación ${ }^{29}$, respecto a los cuales todavía es muy elemental la cultura disponible; como tampoco conocemos la medida en la que queda afectada la construcción de la identidad erótica, de la identidad afectiva, cuando se expande la relación y la comunicación mediada por Internet ${ }^{30}$.

Esta línea de deliberación se puede expandir en multitud de investigaciones. Un ámbito en exploración creciente, en el que nuestro grupo de trabajo promueve investigaciones doctorales $^{31}$, es el de los videojuegos; tanto como espacios multiusuario de prácticas con la identidad, como escenarios pedagógicamente dirigidos a la práctica lúdica, las cual promueve maestría en el dominio de actividad del juego. Con ello, continuamos propuestas como la de $\mathrm{Gee}^{32}$, indagando los principios pedagógicos que los diseñadores aplican para conseguir interesar, sobrepasar con éxito el período inicial de entrenamiento, mantener el interés del jugador, encontrar fuentes importantes de recompensa intrínseca, estimular la curiosidad y las habilidades cognitivas necesarias. En definitiva, entre la práctica que se ejercita en el juego y las prácticas que se ejercitan en las instituciones de formación, la diferencia más relevante es la del dominio en el que tiene lugar la práctica; ambas, respecto a la vida ${ }^{33}$ real, son situaciones fuera de contexto, si se toma como referencia vital, el mundo de la vida. Con ello, no quiero minusvalorar la cuestión del dominio al que se aplica la práctica, porque es culturalmente decisiva; pero, tampoco se puede ocultar que el procedimiento, en aquella práctica lúdica y en esta práctica escolar, tiene una sobresaliente homología. Graciela A. Esnaola denomina a los videojuegos "espacios intersticiales cognitivos", espacios en los que tienen lugar transiciones entre los sujetos y la cultura, en ellos se plasma discursividad social al tiempo que institucionalización de la subjetividad. "El personaje deviene en arquetipo de identificación ya que posibilita al usuario la proyección imaginaria de sus contenidos afectivos"34. De este proceso de identificación en el contexto lúdico no duda nadie. El problema que resta es el de determinar si la identificación es superficial o profunda y las condiciones personales y lúdicas de lo uno o lo otro. La respuesta a este interrogante fundamental requiere antes resolver si la afectación vital del entorno Internet es periférica o densa, tanto en lo positivo (p.e. vinculación social) o en lo negativo (p.e. desvinculación social y anomia)

\section{- Los perjuicios de la práctica comunicativa en Internet}

Fue motivo de controversia la investigación llevada a cabo en la Universidad Carnegie Mellon (1998), conocida como The Home Net Study 1 (1998), en la que parecía confirmarse que la práctica asidua de los niños en Internet generaba tendencias al aislamiento social y a la depresión. Norman Nie (Univ. Stanfor) sostiene, como conclusión de la investigación en el SIQSS "Internet and Society", que la dedicación a Internet está

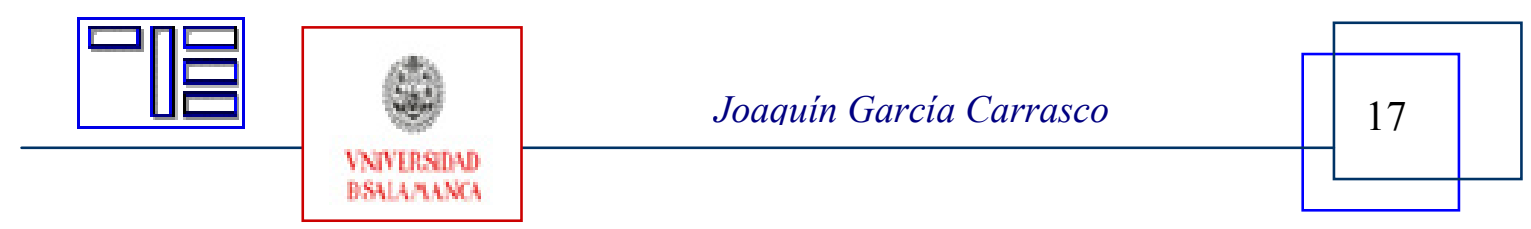


Revista Electrónica Teoría de la Educación.

Educación y Cultura en la Sociedad de la Información.

http://www.usal.es/teoriaeducacion

Vol. 7. No2. Diciembre 2006

generando "soledad y anonimia" ("home alone and anonymous"). Posteriormente los estudios Home Net 2 y Home Net $3^{36}$ no confirmaron esta hipótesis.

Quienes defienden la incidencia disocial de Internet, perspectiva distópica, están convencidos de que en el denominado ciberespacio, la interacción mediada por tecnología digital, no puede dar origen a "comunidades reales", porque roba tiempo a la práctica de la interacción en la "comunidad real" y la debilita; sirvan de muestra dos autores: Baudrillard $^{37}$ y Gergen ${ }^{38}$. Para estos autores las "cibercomunidades" se instituirían dentro de relaciones secundarias, porque los lazos son más efímeros, incluso estaríamos frente a una "inversión" de la tendencia antropológica, mantenida miles años, dedicada al reforzamiento de una vinculación orgánica, que las computadoras transforman de manera creciente en asociación impersonal; el público de los ciudadanos se sustituye por un público de consumidores, transformando las interacciones sociales en el sucedáneo de transacciones de consumo.

R. Putnam llevó a cabo una investigación sobre la variación del "capital social" en la contemporaneidad norteamericana.

“...el capital social guarda relación con los vínculos entre individuos -las redes sociales y las normas de reciprocidad y confianza derivadas de ellas. En este sentido el capital social está estrechamente relacionado con lo que algunos han llamado "virtud cívica" [...] el capital social atiende al hecho de que la virtud cívica posee mayor fuerza cuando está enmarcada en una red densa de relaciones sociales recíprocas" ${ }^{\text {39. }}$.

En los vínculos aludidos juegan un papel importante los compromisos cognitivos con la tecnología y los procedimientos de las prácticas sociales, la vida activa de las comunidades; pero también en esos vínculos tiene un rol decisivo el sistema emocional, mediante el establecimiento de afiliaciones e identificaciones, es la otra cara de la virtud cívica, aquella que está compuesta por los sentimientos de ciudadanía.

\section{- Los beneficios potenciales de los entornos virtuales}

El proyecto americano "Pew Internet and American Life" 40 ha probado más bien que Internet no agrava el aislamiento personal, sino que para muchas personas es fuente de implicación cívica y entorno para relaciones sociales. Para estudiar la sinergia entre la mediación tecnológica y la elaboración de la experiencia se diseñó el Proyecto Sintopia $^{41}$; en este proyecto adquieren relevancia los temas de acceso, participación cívica y comunitaria e interacción y expresión social. En este estudio, los datos obtenidos prueban más bien que las prácticas en la red constituyen una prolongación y potenciación de las rutinas cotidianas: un entorno más en el que transcurre de la vida diaria. Las estadísticas de uso doméstico de Internet demuestran que, entre los usos preferenciales se encuentran aquellos que potencian la comunicación interpersonal con fines sociales. También, el análisis resaltó la importancia de "las bajas de Internet", el incremento creciente de individuos que abandonan su uso.

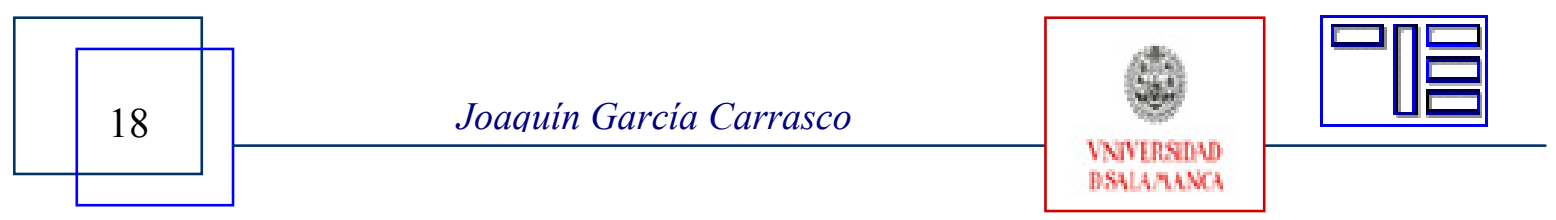


En España se han realizado investigaciones que muestran cómo las relaciones comunicacionales en Internet son también saludables ${ }^{42}$, aunque, como todo escenario comunicacional, también Internet puede dar pie tanto a la comunicación constructiva como a la disruptiva; ni lo uno ni lo otro es consecuencia intrínseca del escenario. No obstante, lo que sí es cierto es que todos los escenarios de prácticas comunicacionales, constituyen oportunidades ambiguas, dado que han de ser gestionados, para que adquieran sentido, por agentes intencionales. También nosotros andamos investigando este punto; la investigación doctoral de Nicole Etchevers Goijberg ${ }^{43}$, se centra sobre la comprensión, la expresión y la interpretación emocional, dentro de las relaciones en Internet.

Hay grupos socialmente limitados para los que la comunicación a mediada por la computadora crea un entorno benéfico para la expansión realizativa del sistema persona. J.W. Turner, entrevistaron a participantes en una "lista", en la cual interaccionaban enfermos con cáncer, constataron "relaciones hipersonales", profundas y con efectos emocionales deseables; proceso que justifican por el emparejamiento óptimo ${ }^{44}$. K.P. Davison extendió la indagación a personas participantes en grupos de autoayuda, agrupaban a pacientes de 20 enfermedades diferentes, pudieron comprobar que cuanto más inhabilitantes socialmente eran las enfermedades, mayor importancia podía adquirir Internet para los procesos de ayuda. De experiencias como éstas obtienen inspiración iniciativas como las denominadas "E-mail mentoring". Internet permite, a personas en aquellas condiciones un desplazamiento y superación de las clausuras que proporciona el estatus, la clase social, las funciones públicas y las limitaciones del carácter.

Si cabe interpretar que la actividad en Internet se presenta como una continuidad de la vida ordinaria, es en la comunidad de vida real donde se juegan los destinos de la Humanidad y el sentido de la vida de cada ser humano. La controversia sobre Internet, en lo que a vida relacional se refiere, puede transformarse en coartada, de los problemas que se generan en aquella: ya es "vida líquida" 45 antes de presentarse en Internet, los sujetos y los grupos llevan su liquidez o solidez pegada a su biografía, cuando navegan por ella. Si el sistema emocional se caracteriza por sus funciones vinculativas, expresivas-comunicativas y valorativas-axiológicas, la solidez de las mismas se pone a prueba, como hemos indicado, cuando la comunidad de observadores en la dramaturgia de la interacción se hace invisible.

La humanidad se caracteriza por su habilidad para la gestión de las oportunidades que contienen los escenarios, a partir de la experiencia deliberada. No otra cosa es la cultura. El ámbito de Internet se presenta como un "no-lugar" que se expande y evoluciona sin otras restricciones que las tecnológicas: una teoría-tecnología de codificación, un sistema lógico para operar en código binario, una tecnología de memoria, una tecnología de teletransmisión, una ingeniería para operar con los componentes anteriores. Es "mundo" de tecnología. En él los seres humanos se presentan como agentes intencionales que gestionan oportunidad -la pierden, la incendian, se construyen o derrumban-, mediante una deliberación constructiva o destructiva sobre la experiencia. Algo análogo se le plantea a los seres humanos respecto a la naturaleza. En el mundo de la naturaleza,

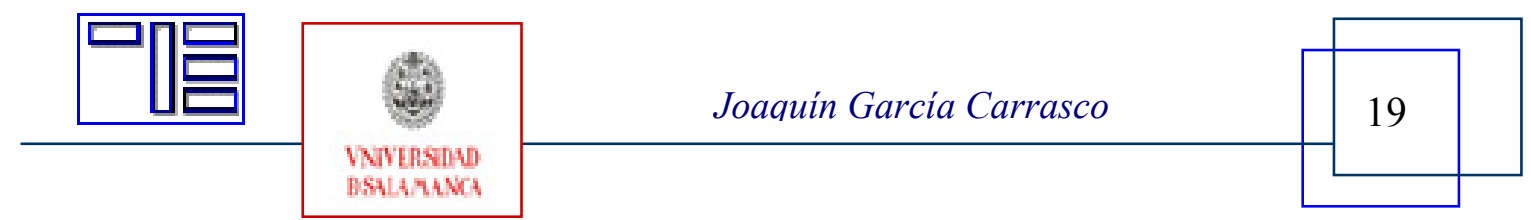


Revista Electrónica Teoría de la Educación.

Educación y Cultura en la Sociedad de la Información.

http://www.usal.es/teoriaeducacion

Vol. 7. No2. Diciembre 2006

como en el mundo de la tecnología, el reto de la cultura estriba en gestionar la oportunidad, fundados en el carácter realizativo, para bien o para mal, de la experiencia. Internet se muestra como un "mundo" con elementales restricciones de accesibilidad (disponer de la tecnología) y con una incipiente cultura disponible. Por eso, nos encontramos en plena controversia acerca de las "instituciones imprescindibles": discutiendo acerca de cuáles y cómo han de ser los proyectos colectivos que han de tomar cuerpo social; desde cómo han de configurarse las funciones de los grupos sociales primarios, a cómo habrán de ser las instituciones de formación, o cómo han de estructurarse los sistemas científicos y tecnológicos. En esta misma línea de investigación que comentamos se sitúan obras como las de P. Wallace ${ }^{46}$, D. Levis ${ }^{47}$, B. Búrdalo ${ }^{48}$ y muchos otros.

Desde el comienzo de la red fue percibida ésta como escenario con un potencial emocional intrínseco -normal, anormal y patológico- enorme ${ }^{49}$. De ahí que no sólo sean pertinentes investigaciones que rastrean el comportamiento emocional en Internet, sino todas aquellas que indagan el sistema emocional y sus roles en el mundo de la vida, como las llevadas a cabo en "Mind and Life Institute",50, donde colaboran personalidades como D. Goleman, el fallecido F. Varela (fue Director del Cognitive Neurosciences and Brain Imaging, en el CNRS francés), P. Ekman, R. Davidson, M. Greenberg; todos ellos con obras de importancia reconocida en el ámbito del sistema emocional ${ }^{51}$.

\section{II-La emoción en las máquinas de cómputo}

Un segundo aspecto de las relaciones entre las nuevas tecnologías y el sistema emocional es el que se centra en el programa denominado "ordenadores emocionales". En este caso la figura más conocida es Rosalind Picard, experta del MIT en "computación afectiva" desde 1987. En este caso serán los ordenadores los que nos preguntarán sobre nuestros estados afectivos y ofrecerán ayuda; es un programa sobre "Things That Think" (artefactos que piensan). El programa pretende completar las funciones actuales del ordenador con aquellas que simulan o emulan el sistema emocional humano, a la hora de la gestión racional de las actividades. Esto ya plantea problemas teóricos importantes. Cuando Turing argumentaba la posibilidad de máquinas inteligentes, formulaba la cuestión de la siguiente manera: que el resultado de la actividad sea considerado producto de la inteligencia, por parte de un observador ignorante de que la operación ha sido realizada por una máquina ${ }^{52}$. Pregunta análoga formula R. Picard en el caso de los estados emocionales: “¿Qué significa para un ordenador tener emociones?"53; pregunta que exige dos cosas: elaborar una teoría general de las emociones y, dentro de ella, identificar mecanismos que puedan reconocerse tanto en las máquinas como en los seres humanos.

Los ingenieros tratan de evitar demorarse en lo primero y buscan estrategias para sumergirse directamente en lo segundo. Para ello, rodean el primer problema, transformando la cuestión de "tener emociones", sentir en primera persona, para centrarse en la cuestión a la que alude el concepto de "empatía"; por este camino "sentir emociones" se delibera en el contexto de las relaciones entre la computadora y el usuario. Se trataría, entonces, de "comportamientos" de la máquina que permiten al usuario atribuirle la

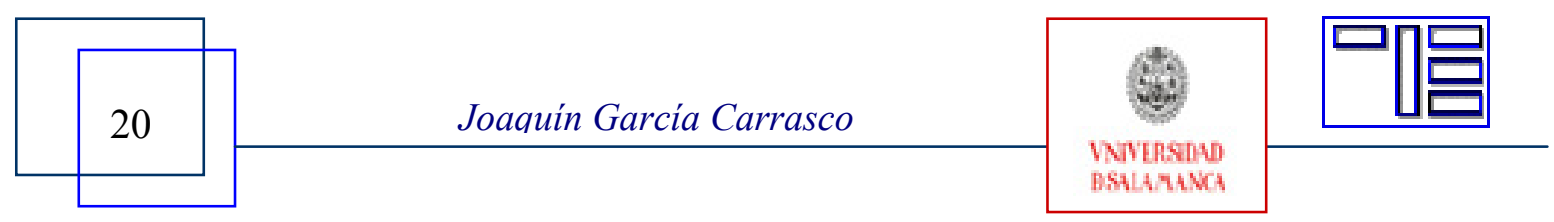


condición de actor emocional - cosa que los niños practican con frecuencia en sus juegos- y de "manifestaciones (indicaciones)" de estados emocionales que podrían ser reconocidos por la máquina. El proyecto intenta que el ordenador pueda interpretar indicaciones acerca de estados emotivos del usuario, ya sea mediante sensores o mediante indicaciones indirectas (fatiga de actividad, resistencia a la tarea, frustración...) ${ }^{54}$. En esta línea de "Affective Computing" la investigación es creciente; de hecho no hace sino precisar el proyecto general de evolución de la tecnología informática en la dirección de familiaridad máquina-usuario ${ }^{55}$.

En España, p.e., el "Laboratorio de Interacción Persona-Computador para Necesidades Especiales (LIPCNE) ${ }^{56}$, en el Departamento de Arquitectura y Tecnología de Computadores de la Facultad de Informática de la UPV-EHU, creado en 1985, se centra en investigaciones de posibilidades tecnológicas para la solución de problemas de comunicación de personas con discapacidad; intentando la mejora de la inserción social y laboral. Se propone la creación de "Interfaces adaptativas persona-computador para personas con necesidades especiales" y "Computación emocional, reconocimiento y síntesis de emociones y aplicación en mediación emocional". Ha desarrollado la interfaz del sistema GESTELE, entre cuyas virtualidades pretende la gestión emocional en esos usuarios con necesidades especiales ${ }^{57}$. Centros análogos se encuentran en la Universidad de Dundee $^{58}$ o en la Universidad Complutense de Madrid ${ }^{59}$. Investigaciones en este sentido han aparecido en "Internacional Journal of Human Computers Studies"60.

El Grupo de "Reconocimiento Facial \& Visión Artificial (FRAV)" de la División de Arquitectura de Computadores (DAC) de la Universidad Rey Juan Carlos, investiga, entre otros temas, "video sensores" para reconocimiento automático de caras y visión artificial para seguridad vial ${ }^{61}$.

En este mismo sentido podrían insertarse cuantas investigaciones y prácticas se dirigen a mejorar la relación entre entorno tecnológico y actor en las prácticas formativas, en vistas a gestionar la mejora de su estado emocional, la implicación emotiva en la tarea, la creación de entornos socioafectivos eficientes para el aprendizaje...etc. Todo ello implica dirigir o transformar los diseños de los entornos o modificar las aplicaciones en vistas a que la tecnología contribuya a la gestión constructiva del sistema emocional y potenciar, por esta vía, los objetivos formativos en los entornos de formación mediados por la tecnología. Entre nosotros, p.e., A.Miguel realiza una investigación doctoral sobre entornos de red facilitadores en familias e instituciones de formación con niños autistas.

\section{III-Las computadoras como instrumentos para la observación de estados emocionales}

La tercera línea de investigación a la que pudiera aludirse tiene que ver con las tecnologías en tanto que instrumentos para el análisis, la comprensión y la gestión de estados emocionales.

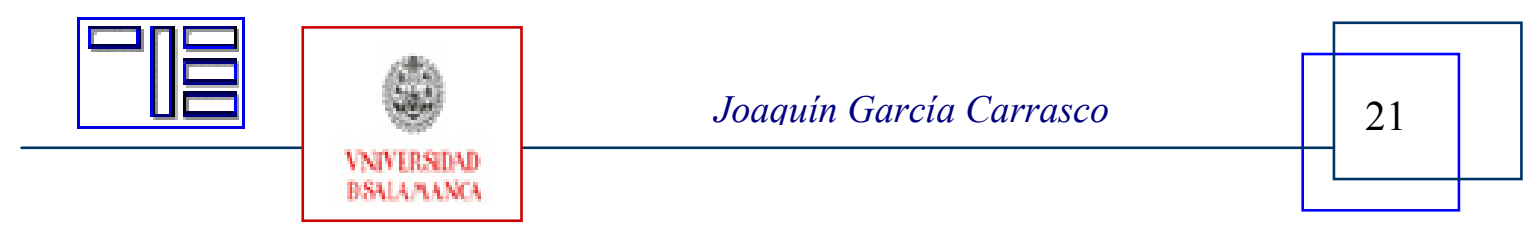


Revista Electrónica Teoría de la Educación.

Educación y Cultura en la Sociedad de la Información.

http://www.usal.es/teoriaeducacion

Vol. 7. No2. Diciembre 2006

Aquí las tecnologías intervienen por su capacidad para la modelización de estados emocionales $^{62}$, investigación que aplica a la construcción de personajes animados, p.e., en películas o videojuegos; afecta tanto a la creación de contextos emocionales, la representación misma de la emoción, y la simulación del comportamiento multimodal correspondiente. Intervienen las palabras y las dimensiones del "appraisal", los signos de la activación emocional del personaje. En estos estudios fue pionero P. Ekman ${ }^{63}$. Se seguían los pasos de Birdwhistell ${ }^{64}$-fundador de la kinésica (el lenguaje del movimiento)- y Hall -fundador de la proxémica (el lenguaje del espacio) ${ }^{65}$. La perspectiva era, en sentido estricto, etológica: análisis de patrones gestuales, patrones de actividad del sistema músculoesquelético, especialmente de los músculos de la cara, como "señal" del estado emocional; en el caso de las denominadas emociones primarias, eran patrones innatos, propios de la especie que podían ser reconocidos en todas las culturas ${ }^{66}$.

Fundados en este criterio de observación etológica se iniciaron investigaciones sobre la identificación de patrones de reconocimiento de estados emocionales diferenciados. La primera advertencia, que ya $\mathrm{W}$. James puso de manifiesto, es la de que el vocabulario, siendo útil para el entendimiento emocional, es poco preciso para la discriminación de estados; en muchas ocasiones no diferencia entre intensidades y categorías; p.e., todos entenderíamos como diferentes alegría y entusiasmo, pudiendo, no obstante pertenecer ambas a misma categoría, variando simplemente el contexto inductor y la intensidad del estado. W. Canon confirmaba igualmente la imposibilidad de segmentación categorial de las emociones acudiendo a variables de activación orgánica y estados viscerales ${ }^{67}$, aun cuando todas las emociones conlleven este acompañamiento ${ }^{68}$.

De ahí que una aportación decisiva fuera la distinción entre estados emocionales de fondo (p.e placer-displacer), emociones primarias y emociones secundarias. Estas últimas son dependientes del contexto inductor, del contexto cultural, de la historia experiencial y su identificación dependiente del vocabulario disponible. Pero, al menos las emociones primarias pueden presentar indicadores discriminantes que la computadora puede detectar. El grupo español de la Universidad Rey Juan Carlos, en este mismo número de la revista, presenta un trabajo sintético sobre diferentes procedimientos de indagación en el tema. La investigación tecnológicamente mediada de las emociones se orienta tanto en la dirección de analizarla mediante recursos sonoros (audiciones que se deben interpretar emocionalmente), estudiando la discriminación (grado de coincidencia) de los estados emocionales que se perciben; mediante recursos visuales, analizando rostros o escenas (p.e.videos). La tecnología puede intervenir como instrumento para la detección y el aislamiento de patrones diferenciados de expresión emocional, como en las investigaciones de P. Ekman sobre expresiones faciales; aquí la tecnología se toma como instrumento para la identificación y para el calibrado de la categorización de estados emocionales; también puede intervenir la tecnología para detectar estados emocionales en los individuos a partir de patrones de señales identificables, incluso en casos en los que, p.e., la observación visual no es instrumento suficientemente fino; de ahí el interés del reconocimiento automático de emociones.

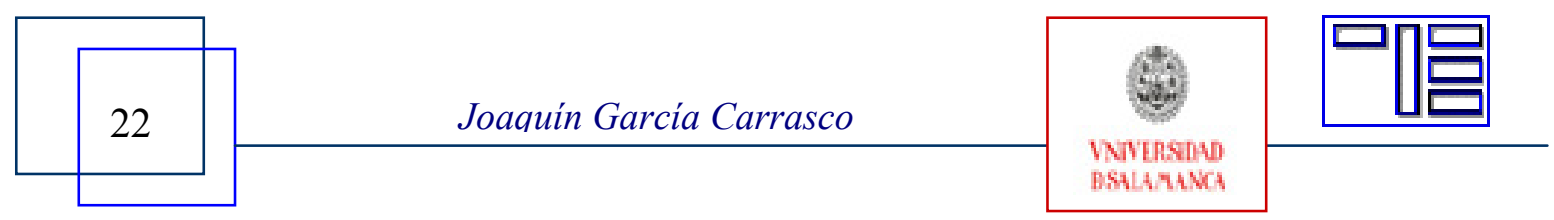


Se abre así un panorama para la investigación de la educación, tanto en la línea de dilucidar cómo las personas establecen sus "mundos" y la medida en la que "el imaginario" aporta a los espacios de actividad que potencian las tecnologías, lo que les falta a éstas para transformarse en "mundos personales" y en "mundos de intimidad".

Para concluir este trabajo añadiríamos que, tal vez, estas investigaciones requieren de un marco teórico general que indague el papel de la imaginación, tanto en el campo de las emociones como en el campo de la tecnología, en vistas a comprender los efectos reales de los entornos virtuales sobre el sistema emocional. La referencia a las funciones mentales de la fantasía está esparcida como sugerencias en muchos libros que estudian las emociones, pero pocos hacen un tratamiento sistemático del problema.

\section{4.- BIBLIOGRAFÍA}

Argyle, K. y Shields, R. (1996). Is there a Body in the Net?. En R. Shields (Ed.). Cultures of internet : virtual spaces, real histories, living bodies. E.U.A., Sage.

BALAGUER, R. (2003) Internet: un nuevo espacio psicosocial. Montevideo, Ed. Trilce.

BATESON, G. (1998) Pasos hacia una ecología de la mente. Buenos Aires, LohléLumen.

BAUDRILLARD, J. (1984) Cultura y simulacro. Barcelona, Kairós.

BAUMAN, Z. (2006) La vida líquida. Paidós, Barcelona.

BIRDWHISTELL, R.L. (1970) Kinesics and context. Philadhelphia, University of Pennsylvania.

BRUNER, J. (1988) Realidad mental y mundos posibles. Los actos de la imaginación que dan sentido a la experiencia. Barcelona,Gedisa.

BUDALO, B. (2000) Amor y sexo en internet. Madrid, Biblioteca Nueva.

COX, H. (1977) Las fiestas de locos. Ensayo sobre el talante festivo y la fantasía. Madrid, Taurus.

EKMAN, P. (2004) ¿Qué dice este gesto?. Barcelona, R.B.A.

GARCÍA CARRASCO, J. (2004) Educación y ética de la calidad de vida en la sociedad de la información En Revista digital Universitaria. UNAM. http://www.revista.unam.mx publicado

http://www.revista.unam.mx/vol.5/num8/art53/art53.htm también puede entrar a través del índice de la revista que está en http://www.revista.unam.mx (5-6-2005).

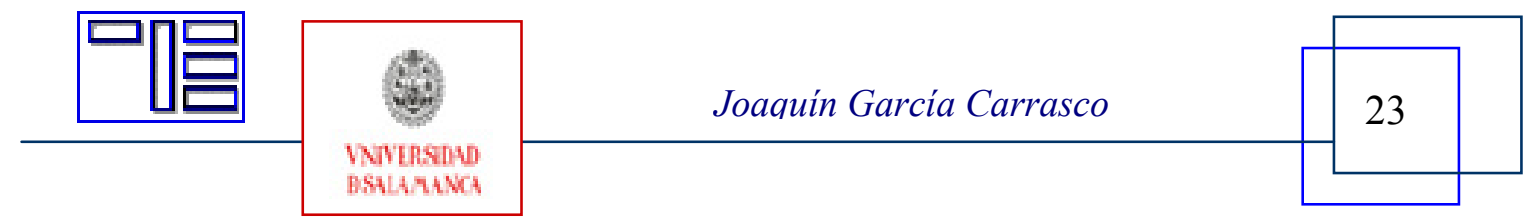


Revista Electrónica Teoría de la Educación.

Educación y Cultura en la Sociedad de la Información.

http://www.usal.es/teoriaeducacion

Vol. 7. No2. Diciembre 2006

GEE, P. (2004) Lo que nos enseñan los videojuegos sobre el aprendizaje y el alfabetismo. Granada, Aljibe.

GERGEN K. (1992) El yo saturado. Dilemas de identidad en el mundo contemporáneo. Barcelona, Paidós.

GIDDENS, A.(1992) La transformación de la intimidad. Sexualidad, amor y erotismo en las sociedades modernas, Madrid: Ediciones Catedra.

GOFFMAN, E. (1997 v.o. 1959) La presentación de la persona en la vida cotidiana. Amorrortu, Buenos Aires.

GWINELL, E. (1998)El@mor en Internet. Barcelona, Ediciones Paidós.

ESNAOLA, G.A. (2006) Claves culturales en la construcción del conocimiento. ¿Qué enseñan los videojuegos?. Buenos Aires, Alfagrama.

KATZ,J.E.-RICE, R.E. (2005) Consecuencias sociales del uso de Internet. Barcelona, UOC.

KOZULIN, A. (2000) Instrumentos psicológicos. La educación desde la perspectiva sociocultural. Paidós, Barcelona.

KOZULIN, A. (1994) La psicología de Vygotski: biografía de unas ideas. Madrid, Alianza.

LEVIS, D. (2005) Amores en red. Relaciones afectivas en la era de Internet. Buenos Aires, Prometeo Libros.

MICHEL, H. (1993) La ontología erótica del ciberespacio. En MICHEL, B. (Edit.) Ciberespacio: los primeros pasos. México, Consejo Nacional de Ciencia y Tecnología

O’DONNELL, J. (2000) Avatares de la palabra. Del papiro al ciberespacio. Barcelona, Paidós.

PICARD, R. (1998) Los ordenadores emocionales. Barcelona, Ariel.

PICARD, R. (2003) What Does it Mean for a Computer to "Have" Emotions?. En TRAPPL, R.. Edt. "Emotions in Humans and Artifacts". Massachussets, MIT Press.

PUTNAM, R.D. (2002) Solo en la bolera: colapso y resurgimiento de la comunidad norteamericana. Barcelona, Círculo de lectores.

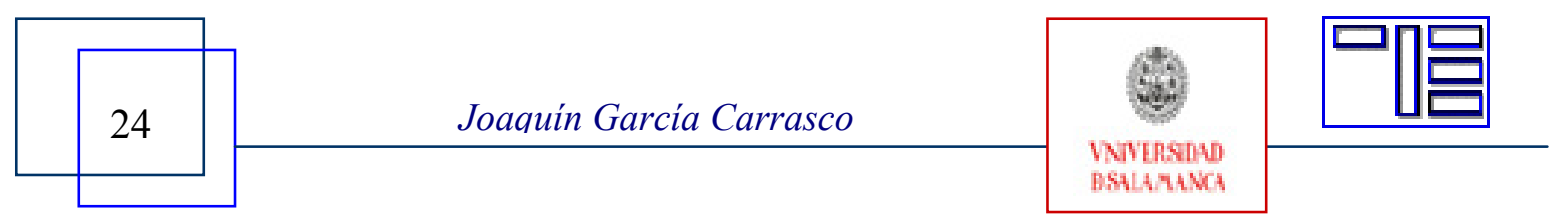


TURING, A. (1974) ¿Puede pensar una máquina?. Valencia, Departamento de Lógica y Filosofía de la Ciencia.

TURKLE, SH. (1984) El segundo yo: las computadoras y el espíritu humano. Buenos Aires, Ediciones Galápago.

TURKLE, SH. (1997) La vida en la pantalla : la construcción de la identidad en la era de Internet. Barcelona, Paidós.

WALLACE, P. (2001) La psicología de Internet. Barcelona, Paidós.

WOLHEIM, R. (2006) Sobre las emociones. Madrid, Antonio Machado Libros.

\section{NOTAS}

[1] BRUNER, J. (1988) Realidad mental y mundos posibles. Los actos de la imaginación que dan sentido a la experiencia. Barcelona,Gedisa.

[2] http://eur-lex.europa.eu/LexUriServ/site/es/com/2006/com2006_0364es01.pdf (20-10-2006)

[3] O’DONNELL, J. (2000) Avatares de la palabra. Del papiro al ciberespacio. Barcelona, Paidós, p.91.

[4] GIDDENS, A.(1992) La transformación de la intimidad. Sexualidad, amor y erotismo en las sociedades modernas, Madrid: Ediciones Catedra.

[5] GWINELL, E. (1998) El @mor en Internet. Barcelona, Ediciones Paidós.

[6] BALAGUER, R. (2003) Internet: un nuevo espacio psicosocial. Montevideo, Ed. Trilce

[7] KOZULIN, A. (2000) Instrumentos psicológicos. La educación desde la perspectiva sociocultural. Paidós, Barcelona.

[8] GOFFMAN, E. (1997 v.o. 1959) La presentación de la persona en la vida cotidiana. Amorrortu, Buenos Aires.

[9] WALLACE, P. (2001) La psicología de Internet. Barcelona, Paidós, p. 320-321.

[10] La historia es real y conozco personalmente a sus protagonistas.

[11] LEVIS, D. (2005) Amores en red. Relaciones afectivas en la era de Internet. Prometeo Libros, Buenos Aires, pp. 38-41.

[12] Financial Times: 8-10-2006.

[13] Ciberp@ís (22-06-2006)

[14] http://www.aimc.es. (3-11-2006)

[15] KOZULIN, A. (1994) La psicología de Vygotsky : biografia de unas ideas. Madrid, Alianza.

[16] BATESON, G. (1998) Pasos hacia una ecología de la mente. Buenos Aires, Lohlé-Lumen

[17] TURKLE, SH. (1997) La vida en la pantalla: la construcción de la identidad en la era de Internet. Barcelona, Paidós.

[18] TURKLE, SH. (1984) El segundo yo: las computadoras y el espiritu humano. Buenos Aires, Ediciones Galápago.

[19] http://es.wikipedia.org/wiki/MUD

[20] http://caronte.quintadimension.com/Juegos/Mud/

[21] http://es.wikipedia.org/wiki/Mod (movimiento juvenil)

[22] http://www.mod-pc.com/modules.php?name=Comunidad

[23] http://en.wikipedia.org/wiki/MOO

[24] COX, H. (1977) Las fiestas de locos. Ensayo sobre el talante festivo y la fantasía. Madrid, Taurus.

[25] WOLHEIM, R. (2006) Sobre las emociones. Madrid, Antonio Machado Libros. Especialmente el capítulo "Sobre las llamadas emociones morales".

[26] TURKLE, SH. : “ http://biblioweb.sindominio.net/telematica/mud.html (19-10-2006)

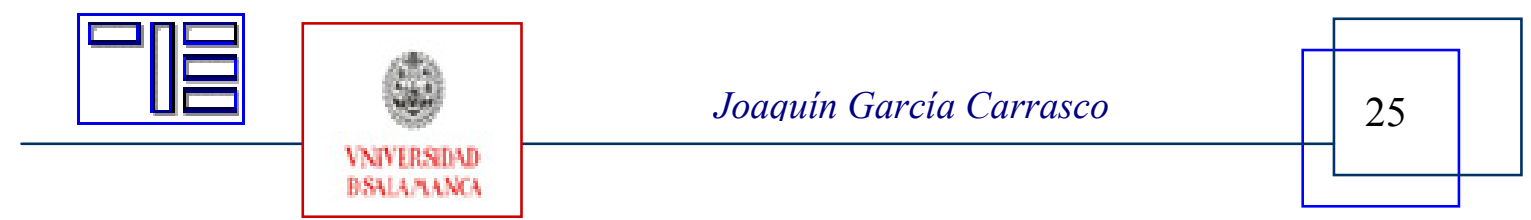


Revista Electrónica Teoría de la Educación.

Educación y Cultura en la Sociedad de la Información.

http://www.usal.es/teoriaeducacion

Vol. 7. No2. Diciembre 2006

[27] GARCÍA CARRASCO, J. (2004) Educación y ética de la calidad de vida en la sociedad de la información En Revista digital Universitaria. UNAM. http://www.revista.unam.mx publicado http://www.revista.unam.mx/vol.5/num8/art53/art53.htm también puede entrar a través del índice de la revista que está en http://www.revista.unam.mx

[28] Roco, Gladys, 2001, Un estudio del establecimiento de relaciones intimas mediadas por computador. El caso de IRC en Internet, Revista TEXTOS de la CiberSociedad, 1. Temática Variada. Disponible en http://www.cibersociedad.net (26-10-2006)

[29] Mora Castañeda, Belvy, 2003, Rituales de simulación y sociabilidad virtual. Una aproximación a los procesos de construcción de emociones en la Red, Revista TEXTOS de la CiberSociedad, 2. Temática Variada. Disponible en http://www.cibersociedad.net_(26-10-2006)

[30] Argyle, K. y Shields, R. (1996). Is there a Body in the Net?. En R. Shields (Ed.). Cultures of internet : virtual spaces, real histories, living bodies. E.U.A.: Sage.

[31] P.e., MARCANO, B. "Factores emocionales en los videojuegos de guerra" (2006) (inédito)

[32] GEE, P. (2004) Lo que nos enseñan los videojuegos sobre el aprendizaje y el alfabetismo. Granada, Aljibe.

[33]ESNAOLA, G.A. (2006) Claves culturales en la construcción del conocimiento. ¿Qué enseñan los videojuegos?. Buenos Aires, Alfagrama.

[34] Id. Id. P.140.

[35] http://www.stanford.edu/group/siqss/Press_Release/internetStudy.html (6-11-2006)

[36] Kraut, R. \& Kiesler, S. (2003) Psychological Science Agenda. Science Briefs Verano 2003. Véanse los comentarios de Nicole Etchevers Goijberg, en “¿Dónde están las emociones en el Ciberespacio? Análisis de la situación actual”: http://www.cibersociedad.net/textos/revista.php?num=5 Esta autora también realiza una investigación de doctorado sobre el tema de las emociones en el ámbito de la comunicación digital, dentro de nuestro de nuestro programa de doctorado, en la Universidad de Salamanca.

[37] BAUDRILLARD, J. (1984) Cultura y simulacro. Barcelona, Cairos.

[38] GERGEN K. (1992) El yo saturado. Dilemas de identidad en el mundo contemporáneo. Barcelona, Paidós.

[39] PUTNAM, R.D. (2002) Solo en la bolera: colapso y resurgimiento de la comunidad norteamericana. Barcelona, Círculo de lectores, p. 14.

[40]http://www.pewinternet.org/

[41] KATZ,J.E.-RICE, R.E. (2005) Consecuencias sociales del uso de Internet. Barcelona, UOC.

[42] Peris, R., Gimeno, M., Pinazo, D., Ortet, G., Carrero, V., Sanchiz, M. e Ibáñez, I. (2002) Cyberpsychology \& Behavior 5.

Disponible en: http://juno.ingentaselect.com/vl=181213/cl=131/nw=1/rpsv/cw/mal/10949313/contp1.htm [43]Etchevers Goijberg, Nicole, 2005, ¿Dónde están las emociones en el Ciberespacio? Análisis de la situación actual, Revista TEXTOS de la CiberSociedad, 5. Temática Variada. Disponible en http://www.cibersociedad.net; I.id. 2005, "Ruta Etnográfica para la Comprensión de la Comunicación Online". Publicado en la revista electrónica DIM, Año 1, n 1, Junio del 2005. Disponible en el ARCHIVO del Observatorio para la CiberSociedad en http://www.cibersociedad.net/archivo/articulo.php?art=204; Id.id., 2005, "El destape de las ciberrelaciones":

http://www.cibersociedad.net/recursos/art_div.php?id=122;

[44] TURNER, J.W.-GRUBE, J.A.-MEȲERS, J. (2001) Developing an optimal match within online communities: an exploration of CMC support communities and traditional support. En Rv. Journal of Communication, Junio - Vol. 51, t. 2, pp. 231-449. Se puede consultar el texto en PDF: http://www.blackwell-synergy.com/toc/jcom/51/2

[45] BAUMAN, Z. (2006) La vida líquida. Paidós, Barcelona.

[46] WALLACE, P. (2001) La psicología de Internet. Barcelona, Paidós.

[47]LEVIS, D. (2005) Amores en red. Relaciones afectivas en la era de Internet. Buenos Aires, Prometeo Libros.

[48] BUDALO, B. (2000) Amor y sexo en internet. Madrid, Biblioteca Nueva.

[49] MICHEL, H. (1993) La ontología erótica del ciberespacio. En MICHEL, B. (Edit.) Ciberespacio: los primeros pasos. México, Consejo Nacional de Ciencia y Tecnología.pp.61-79

[50] http://www.mindandlife.org/ .

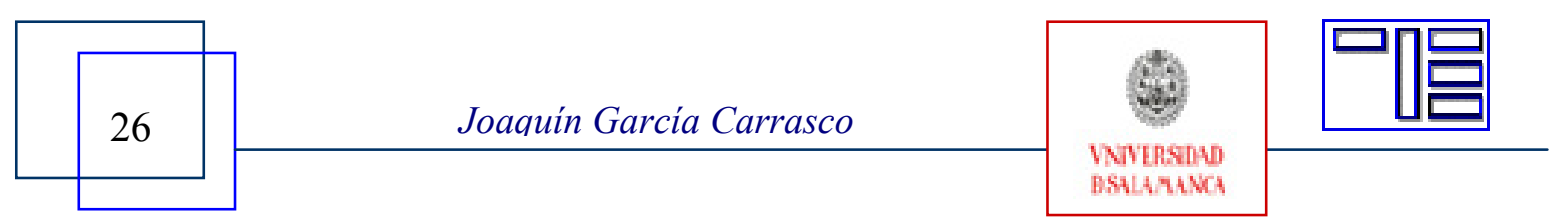


[51] Fruto de la reunión del Seminario (2001) fue la obra: GOLEMAN, D. Edit (2003) Emociones destructivas. Barcelona, Kairós.

[52] TURING, A. (1974) ¿Puede pensar una máquina?. Valencia, Departamento de Lógica y Filosofía de la Ciencia.

[53] PICARD, R. (2003) What Does it Mean for a Computer to "Have” Emotions?. En TRAPPL, R.. Edt. "Emotions in Humans and Artifacts". Massachussets, MIT Press.

[54] PICARD, R. (1998) Los ordenadores emocionales. Barcelona, Ariel

[55] http://affect.media.mit.edu/ (19-10-2006). En esta dirección se describe el grupo de investigación y las publicaciones del mismo.

[56] http://www.sc.ehu.es/acwbbpke/

[57] http://www.sc.ehu.es/acwbbpke/Publicaciones\%20LIPCNE.html (23-10-2006)

[58] " Department of Applied Computing”, University of Dundee, Scotland. http://www.computing.dundee.ac.uk .

[59] Departamento de Ingeniería Electrónica-E.T.S.I. Telecomunicación-Universidad Politécnica de Madrid. http://www-gth.die.upm.es/ y http://www.die.upm.es/

[60]

http://www.elsevier.com/wps/find/journalspecialissues.cws_home/622846/specialissues\#specialissues

[61] http://frav.escet.urjc.es/principal.html

[62] http://www.limsi.fr/Individu/sarkis/publications/cjesc 2005.pdf

[63] EKMAN, P. (2004) ¿Qué dice este gesto?. Barcelona, R.B.A.

[64] BIRDWHISTELL, R.L. (1970) Kinesics and context. Philadhelphia, University of Pennsylvania.

[65] HALL, E.T. (1989) El lenguaje silencioso. Madrid, Alianza Editorial. Para un estudio descriptivo de la problemática véase: http://www.ugr.es/ pwlac/G19 19Helena_AlvarezDeArcaya_Ajuria.html (23-102006)

[66] EIBL-EIBESFELDT, I. (1993) Biología del comportamiento humano: manual de etología humana. Madrid. Alianza.

[67] GARCIA CARRASCO, J.-GARCIA DEL DUJO, A. (2001) Teoría de la educación. T.II. Procesos primarios de formación del pensamiento y la acción. Editorial Universidad de Salamanca, Salamanca, cap. IX.

[68] DAMASIO, A. (1996) El error de Descartes. La emoción, la razón y el cerebro humano. Barcelona, Grijalbo- Mondadori.

\section{Para citar este artículo puede utilizar la siguiente referencia.}

GARCÍA CARRASCO, Joaquín. (2006): Las emociones en el "territorio" on-line. GARCÍA CARRASCO, Joaquín (Coord.) Estudio de los comportamientos emocionales en la red [monográfico en línea]. Revista electrónica Teoría de la Educación: Educación y Cultura en la sociedad de la información. Vol. 7, $\mathrm{n}^{\circ} 2$. Universidad de Salamanca. [Fecha de consulta: dd/mm/aaaa]. <http://www.usal.es/ teoriaeducacion/rev_numero_07_02/n7_02_joaquin_garcia.pdf > ISSN 1138-9737

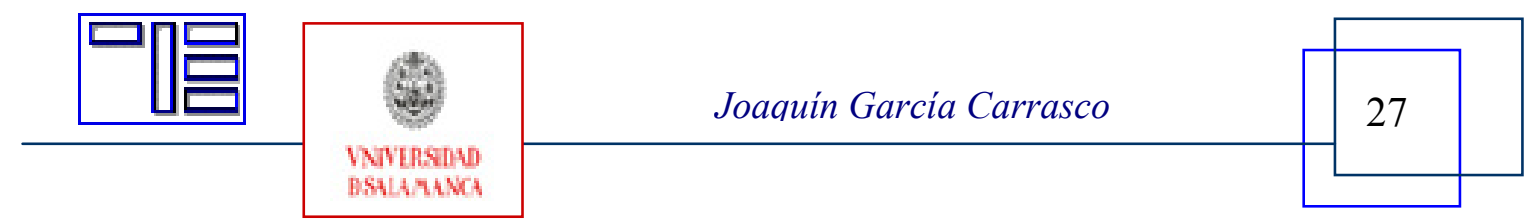

